\title{
Mostrar y comunicar, misión de la Revista Digital Universitaria
}

\author{
Ana María del Pilar Martínez Hernández
}

\begin{abstract}
"Internet es resultado de un proceso tecnológico, que no sólo ha transformado las formas de comunicación, la transmisión de información y las relaciones sociales, sino también el quehacer académico y científico. Las publicaciones digitales son un rubro que había que explorar en la UNAM, y la publicación de la Revista Digital Universitaria, como la primera en su tipo, se emprendió gracias a la confianza que los universitarios depositan en proyectos visionarios y de innovación"
\end{abstract}

Adrián Estrada Corona

E

próximo 31 de marzo se cumplirá el aniversario número 21 de la Revista Digital Universitaria, RDU, primera publicación periódica digital que, desde un enfoque experimental, creó la Universidad Nacional Autónoma de México (UnAm) en el año 2000, con los siguientes objetivos:

- Construir un espacio de innovación, desarrollo, aplicación y formación en publicación digital para artículos de investigación, análisis, creación y reflexión.

- Difundir mediante recursos digitales la investigación, el análisis, la creación y la reflexión universitaria entre la sociedad mexicana e internacional.

- Formar una comunidad virtual alrededor de la revista, que permita establecer vínculos entre autores, editores y lectores (Objetivos, 2000).

Sin lugar a dudas, podemos decir que la RDu ha cumplido cabalmente los propósitos para los que fue creada. Desde el primer número, curiosamente denominado "cero", hasta el que ahora se está leyendo, se han publicado un total de 202 números.

En aquel inicial podía leerse la frase: "El quehacer universitario en línea", la cual daba cuenta del sentido inicial de ser un medio decidido a dar a conocer la riqueza de la producción académica, del trabajo heurístico continuo, creativo e innovador, en una enorme variedad de campos, problemáticas y enfoques interpretativos de la comunidad universitaria. Esto muestra en los hechos el interés por divulgar el material de vanguardia producido en la institución, con un sentido cada vez más cercano al de la comunicación social de la ciencia.

Dol: http://doi.org/10.22201/cuaieed.16076079e.2021.22.2.0 
Hacemos un reconocimiento expreso a todas y todos aquellos universitarios que prospectaron con claridad el avance vertiginoso de la tecnología y la importancia de introducir a la Universidad en el uso de los recursos y herramientas digitales, y de su incorporación en el movimiento internacional que permitiría a la unAm darse a conocer más ampliamente y vincularse con el mundo exterior.

En ese sentido, la RDu fue un proyecto que se anticipó a ese movimiento que prontamente abarcó al planeta entero. Pensada y creada por el doctor Víctor Guerra Ortiz —en conjunto con un grupo de universitarios pioneros en el campo-, al frente de la entonces Dirección General de Servicios de Cómputo Académico (DGSCA), él convenció a las autoridades universitarias de introducir las Tecnologías de la Información y la Comunicación en las tareas sustantivas de la institución, y a la vez visualizó la importancia de crear la primera revista digital en nuestro medio, como una estrategia institucional de vanguardia para hacer acto de presencia y mostrar al mundo el saber producido en la UNAM.

La RDU ha pasado por varias épocas a lo largo de sus dos décadas de aparición; las cuales han estado íntimamente ligadas a la evolución de la tecnología. Estuvo albergada en DGSCA de 2000 a 2010, instancia que ese último año se transformó en la Dirección General de Cómputo y de Tecnologías de Información y Comunicación (DGTIC). A partir de abril de 2017 fue transferida a la Coordinación de Desarrollo Educativo e Innovación Curricular (CODEIC). Y desde junio del año 2020 se encuentra alojada en la recién creada Coordinación de Universidad Abierta, Innovación Educativa y Educación a Distancia (CUAIEED).

Las variaciones se han debido a criterios relacionados con el tipo de material a publicar: artículos, proyectos, semblanzas y entrevistas, reseñas, materiales interactivos, audios y videos, entre otros. Asimismo, la periodicidad de su aparición ha oscilado entre lo mensual, bimestral y trimestral. De igual manera, ha cambiado la diversidad - la unicidad de las temáticas a tratar por número; el primero de los casos abarcó 4 años, de 2000 a 2004; el segundo, 11, de 2005 a 2016. En la fase más reciente, de 2017 a 2021, se ha optado por una combinación de ambas modalidades, recurriendo a la monotemática cuando la situación contemporánea lo ha demandado. Así, se han tenido números dedicados a la inteligencia artificial, la violencia de género o la covid-19.

Como ya se dijo, hasta el momento se han publicado 202 números, incluido el presente. Si consideramos que en cada uno aparecen entre 7 y 10 materiales publicados, a final de cuentas encontramos que, a lo largo de su existencia, en la rDu se ha publicado un mínimo de 1,400 materiales, y más de 2,000, como máximo.

En la actualidad, nuestros autores y autoras, entre 2019 y 2020, provienen en su gran mayoría de la unAm: de institutos y centros, facultades y escuelas (lo mismo del bachillerato que de los niveles profesionales y el posgrado), y de dependencias como la DGTIC y la CUAIEED. También se reciben continuamente contribuciones de diversas instituciones de educación superior de prácticamente todos los estados de la República. Asimismo, llegan artículos provenientes de los Estados Unidos de Norteamérica, Canadá, Alemania, Reino Unido, Holanda y Argentina, entre otros países. 
En lo referente a nuestros lectores y lectoras, en estos mismos años, 2019 y 2020, sabemos que nos leen más mujeres (65.1\% en 2019,69.5\% en 2020) que hombres (34.9\% en 2019, 30.5\% en 2020); que sus rangos de edad oscilan de los 18 a los 65 años y más. No obstante, quienes más nos visitan se encuentran en el rango de 25 a 34 años. También conocemos que aproximadamente 75\% de nuestro público proviene de nuestro país, 2\% de Estados Unidos de Norteamérica, 1.8\% de España y el resto -21.2\% - de América Latina, principalmente de Colombia, Perú, Argentina, Ecuador, Chile, Bolivia, Venezuela y Guatemala.

No son datos menores los que hemos expuesto en los párrafos anteriores acerca de nuestra entrañable e indispensable publicación: la RDu es la primera revista digital de la unAm y cumple 21 años de aparición ininterrumpida. Es una publicación arbitrada e indexada en la que se han abordado temáticas que conjuntan todas las áreas del conocimiento, todas las problemáticas que ocupan o preocupan a la comunidad universitaria, mexicana y a la humanidad entera. En sus contenidos se han presentado todas las posturas y los enfoques clásicos, así como los más vanguardistas, innovadores y disruptivos; más existenciales y universales; asombrosos, confrontativos, dolorosos o motivadores, para conocer, asombrar y mover a la acción; todos aquellos asuntos resultado de la capacidad humana de observar con mirada penetrante aquello que nos "dice" el mundo natural, el social y el humanístico que nos rodea. De ahí que podamos afirmar que la misión de la RDU, que es mostrar y comunicar, se ha cumplido y se cumple justamente, y que ello puede marcar para sus visitantes la diferencia, el antes y el después de la aproximación a una lectura que nos conmueve.

Por todo ello, les invitamos a que nos acompañeny revisen las doce contribuciones que conforman este número 202, multitemático. En la sección Varietas se publican seis trabajos que, desde distintos campos del conocimiento, nos introducen en temas de vanguardia y de asombro, de reflexión urgente o de discusión obligada.

En el primero de ellos, Héctor Hugo Cerecedo Núñez y Patricia Padilla Sosa, ambos de la Facultad de Física de la Universidad Veracruzana, presentan el artículo "Física aplicada: apoyo al combate de la pandemia covid-19", en el cual plantean cómo a través de la aplicación de métodos y conceptos, pruebas experimentales y sus resultados, propios de esta disciplina, se está apoyando al entendimiento del virus SARS-CoV-2, causante de la enfermedad covid-19, así como la manera de combatirlo. Desde su perspectiva, la física aplicada ha contribuido a comprender el origen del virus, su composición y estructura, y sus formas de contagio y de propagación. Además, desde este conocimiento se puede proponer un control de su acción e, inclusive, una posible cura.

El siguiente artículo, "Disfunciones cognitivas en adultos mayores con depresión”, escrito por Jorge Darío López Sánchez y Dora Elizabeth Granados Ramos, de la Universidad Veracruzana, describe las disfunciones cognitivas significativas presentes en adultos mayores con depresión, los tratamientos usuales basados en Inhibidores Selectivos de la Recaptación de Serotonina (ISRS), las limitaciones que éstos presentan y las pautas de tratamiento alternativo que los autores proponen. 
Por su parte, Rafael Antonio López Martínez, Raquel Daza y Rocío Alcántara, del Instituto de Geología de la UnAm y de la Facultad de Ciencias de la UAm, en su artículo "Cuevas volcánicas: entre la realidad y la ficción”, narran el proceso de investigación y los resultados obtenidos en el estudio del tubo de lava de Chimalacatepec, en México. Se trata de una de las pocas investigaciones de este tipo realizadas en nuestro contexto, que les ha permitido descubrir y estudiar la multiplicidad de microorganismos únicos en este tipo de hábitats, y su potencial para comprender más sobre el origen de la vida, o la posibilidad de hacer comparaciones futuras de formas de vida en otros planetas, como Marte, con condiciones extremas.

"Conchas marinas: exquisitos termómetros", es un texto de Javier MedinaSánchez, quien desde la investigación que realiza en la Universidad de Stirling, Escocia, da a conocer una novedosa técnica de isótopos estables agregados (clumped isotopes), a través de la cual se puede conocer la temperatura del agua en la que se formaron las conchas marinas. Esta sofisticada técnica permite analizar las diferencias entre las masas de la multitud de átomos de oxígeno y carbono que las componen.

En el artículo "¿Hacia una nueva 'tabla periódica'?", elaborado por Iván de Jesús Arellano Palma, estudiante de la Maestría en Filosofía de la Ciencia de la unAm, se hace un reconocimiento de la tabla periódica de elementos creada hace 150 años por el químico ruso Mendeléiev, cuya validez y valor han sido incuestionables. Señala, sin embargo, que durante ese tiempo dicha tabla sólo ha sufrido cambios mínimos, como el del acomodo de los elementos de acuerdo con la masa atómica, al del número atómico, que propuso el físico Henry Moseley. Y se atreve a plantear algunas preguntas como las siguientes: ¿algún día existirá un reemplazo a esta tabla periódica? Y si lo hubiera, ¿cuáles serían las razones para ello?

En el último de los trabajos de la sección, "¿Héroes o villanos? Azúcares en la salud y la enfermedad", Ángela Ávila Fernández, Sandra del Moral y María Elena Ortiz-Soto, de la Universidad Juárez Autónoma de Tabasco, el Instituto Tecnológico de Veracruz y la Universidad de Würzburg, Alemania, respectivamente, plantean la errónea y generalizada asociación que considera a los azúcares como nocivos para nuestra salud y causa principal de enfermedades como la caries, diabetes y obesidad. En redes sociales, blogs y revistas, se refuerza frecuentemente esta idea de que los azúcares son los "villanos malvados" que tenemos que evitar. Sin embargo, se desconoce que, además de los relacionados con la dieta, existen otros azúcares con gran diversidad funcional, cuyo papel es fundamental en varios eventos fisiológicos y patológicos, pues ellos son los que los dirigen, regulan o acompañan, y su ausencia tiene efectos en la salud y la enfermedad.

En la sección Universidades, en el trabajo titulado "Transición de la educación media superior a la educación superior: estudio en la unam", los autores Melchor Sánchez, Careli Herrera, Enrique Buzo, Manuel García, Marypaola Maya y Adrián Martínez, presentan un estudio de seguimiento de las trayectorias escolares de los estudiantes universitarios que pasan de la educación media superior a la superior, 
el cual explora el desempeño escolar y la eficiencia terminal de los estudiantes de la generación 2009 del bachillerato de la unam (tanto de la Escuela Nacional Preparatoria como del Colegio de Ciencias y Humanidades), a lo largo de su paso por dicho nivel educativo, y la interrelación con su desempeño escolar y regularidad durante el primer año de la licenciatura. Los resultados de estos estudios son de relevancia ya que permiten identificar, desarrollar e impulsar, de manera precisa, las necesidades de acompañamiento al estudiantado, con el fin de abatir el abandono y el rezago escolares en el nivel profesional.

Por su parte, en la colaboración “Trabajo social en la educación: el futuro del bienestar infantill", Julio César Matus Avendaño, Lizbeth Alejandra Cornejo Hernández y Valeria López Pérez, de la Escuela Nacional de Trabajo Social de la unAM, exponen la importancia y facetas de la participación de los profesionales de este campo en el logro de los objetivos que se plantean las instituciones educativas, destinadas a ofrecer educación básica, la cual, en nuestro contexto, incluye la educación inicial y los niveles preescolar, primaria y secundaria.

En la última contribución de esta sección, Larisa Enríquez Vázquez y Myrna Hernández Gutiérrez, de la cuAIEed, nos presentan el artículo "Alumnos en pandemia: una mirada desde el aprendizaje autónomo", en el cual exponen los resultados obtenidos en un estudio que inició en el marco de la pandemia de la covid-19, en el que durante el mes de mayo de 2020 se aplicó el Cuestionario Aprendizaje autónomo en tiempos de covid-19. Este estudio, centrado en el concepto de aprendizaje autónomo, considera formar a las y los estudiantes como aprendices autogestivos permanentes, con la capacidad de tomar el control y regular sus procesos de aprendizaje para el resto de la vida.

En la sección Continuum educativo se presentan dos artículos. El primero de ellos es la colaboración de Jesús Carlos Salazar Peña, académico de la Universidad Autónoma de Madrid, quien da a conocer "AlfaBtics para la mejora de habilidades y conocimientos digitales", un curso digital multimedia que ha permitido capacitar al profesorado en los procesos de adaptación, comprensión, aplicación e implementación de las tecnologías en la educación. AlfaBtics es una herramienta que permite a los profesores comprender algunos elementos básicos, tales como la interfaz de usuario, la navegación por internet y la búsqueda, así como el uso y presentación de información en la práctica docente, en beneficio del aprendizaje del estudiantado.

Por su parte, Jesús Martínez Pérez y Berenice Martínez Cuatepotzo, docentes de la Facultad de Química de la unam y del сcH Sur, respectivamente, proponen dos estrategias para la enseñanza de la química en el nivel medio superior, mismas que utilizan como herramientas principales el teléfono inteligente (smartphone) y la fotografía. Desde su experiencia, nos muestran "La fotografía en el aula de ciencias: propuestas didácticas", las que, además de lograr los aprendizajes estipulados en los programas de estudios, permiten que el estudiante se relacione con su entorno y desarrolle habilidades de expresión escrita y de intercambio de ideas. 
Finalmente, en la sección Caleidoscopio, Federico Morales Corona nos comparte un podcast titulado "¿Cómo prevenir la caries dental?". Éste es resultado de un ejercicio de divulgación en medios digitales, en el que se reúnen el conocimiento del especialista, la voluntad de compartir información, y el esfuerzo y creatividad implicados es crear un producto de difusión, que pueda llegar a todos y que logre ser atractivo.

Como puede verse, los doce trabajos de que se compone este número marzoabril de 2021 presentan temas para todas y todos. Les invitamos a leernos a su ritmo, desde sus puntos de interés, y a retroalimentar con sus comentarios nuestro quehacer y el de nuestras autoras y autores.

\section{Referencias}

* Estrada Corona, A. (2015, 1 de marzo). Revista Digital Universitaria: 15 años del quehacer universitario en línea. Revista Digital Universitaria, 16(3). http://www.revista.unam.mx/ vol.16/num3/art17/art17.pdf

- Del Ángel Martínez, R. M. y Carranco Arenas, M. P. (2020, 11 de septiembre). Comité editorial Revista Digital Universitaria [diapositivas]. Revista Digital Universitaria.

- Objetivos. (2000). Revista Digital Universitaria, 1(1). http://www.revista.unam.mx/vol.1/

\section{Ana María del Pilar Martínez Hernández}

Licenciada, maestra y doctorante en Pedagogía por la Facultad de Filosofía y Letras (FFYL) de la Universidad Nacional Autónoma de México (UNAM). Profesora de carrera en el Colegio de Pedagogía de la fFYL. Ha participado en actividades de planeación y gestión en diversas instancias universitarias. Fungió como consejera universitaria. Ha impartido y coordinado diversos procesos de formación de docentes. Es la encargada de la Dirección de Innovación Educativa, Desarrollo Curricular y Formación Docente de la Coordinación de Universidad Abierta, Innovación Educativa y Educación a Distancia (CUAIEED) de la UNAM, así como Editora en jefe de la Revista Digital Universitaria.

\section{Cómo citar este artículo}

- Martínez Hernández, Ana María del Pilar. (2021, marzo-abril). Mostrar y comunicar, misión de la Revista Digital Universitaria. Revista Digital Universitaria (RDU), 22(2). doi: http:// doi.org/10.22201/cuaieed.16076079e.2021.22.2.0 